\title{
THE PERCEPTION OF
}

NEIGHBORHOOD DISORDER IN

FLEMISH BELGIUM: DIFFERENCES

BETWEEN ETHNIC MAJORITY AND

MINORITY GROUP MEMBERS AND

BEARING ON FEAR OF CRIME

\author{
Kris Vancluysen, Maarten Van Craen, and \\ Johan Ackaert \\ Hasselt University, Belgium
}

The present research examines whether the perception of neighborhood disorder differs between ethnic majority and minority group members and whether perceived disorder has the same impact on fear of crime among ethnic minorities as among the majority group. To answer the research questions, data are used from a survey among persons of Moroccan, Turkish, and Flemish descent $(n=960)$, gathered in three Flemish Belgian cities (Antwerp, Genk, and Ghent). Multiple regression analyses show differences between majority and minority group members with regard to the perception of loitering youths, dog mess, and littering. Also, results provide support for the broken windows hypothesis in all ethnic groups, but the impact of perceived disorder on fear of crime is highest among the Flemish majority. Possible explanations are discussed. (c) 2010 Wiley Periodicals, Inc.

\section{INTRODUCTION}

In recent decades, the concept of disorder has received a great deal of attention in many disciplines, including criminology, sociology, and social psychology. A number of

\footnotetext{
This research was conducted at SEIN (Identity, Diversity and Inequality Research), a research institute of the Faculty of Business Economics. It was funded by the Flemish Minister of Civic Integration, as part of the Policy Research Centre on Equal Opportunities (Steunpunt Gelijkekansenbeleid). The authors thank the editor and reviewers for their helpful comments.

Correspondence to: Kris Vancluysen, Hasselt University, SEIN, Agoralaan, Building D, Diepenbeek, Belgium, 3590. E-mail: kris.vancluysen@uhasselt.be
} 
studies focused on the influence of individual and contextual characteristics on individuals' perception of disorder (e.g., Reisig \& Cancino, 2004; Sampson \& Raudenbush, 2004; Latkin, German, Hua, \& Curry, 2009) or investigated the relation between perceived disorder and fear of crime (e.g., Taylor, Shumaker, \& Gottfredson, 1985; Ross \& Jang, 2000; Wyant, 2008). Despite the large body of literature, there has been little research on the differences in perceived disorder between ethnic majority and minority groups, on the one hand, and, on the other, whether perceived disorder has a different effect on fear of crime among these groups.

To address this void in the literature, the present research examines the perceptions of neighborhood disorder and their impact on fear of crime among members of Moroccan and Turkish communities and a Flemish reference group living in three Flemish Belgian cities (Antwerp, Genk, and Ghent). Ethnic minorities are of particular interest for research on perceived disorder because members of minority groups (especially juveniles) are often regarded as responsible for causing disorder or delinquent behavior (Bovenkerk, 2001; Werdmölder, 2006; Paoli \& Reuter, 2008). The extent to which ethnic minority group members perceive disorder has been less examined, especially in Europe. Yet, this question is relevant to any understanding of problems of disorder in a multicultural society in its complexity. The research questions of the present study are as follows: (a) Does the perception of neighborhood disorder differ between majority and minority group members? and (b) Does perceived neighborhood disorder have the same impact on fear of crime among minority group members as among majority group members?

\section{LITERATURE OVERVIEW}

\section{The Concept of Disorder}

A glance at the literature makes it immediately apparent that disorder has no single, straightforward definition and is subject to a multiplicity of conceptualizations. In his call for a conceptual definition, Kubrin (2008, p. 205) puts it as follows: "Variability in how disorder is understood and conceptualized across studies is the rule rather than the exception".

LaGrange, Ferraro, and Supancic (1992, p. 312) define disorder as "low-level breaches of community standards that signal an erosion of conventionally accepted norms and values". This definition suggests that a distinction should be made between disorder and (serious) forms of crime (such as murder, theft, breaking-and-entering, assault, and rape). Ross and Mirowsky (1999), however, take the view that although serious crimes are less frequent and less visible, they constitute the extreme end of a “disorder continuum" (p. 414). Sampson and Raudenbush (1999, p. 608) agree and state that "public disorder and predatory crimes are manifestations of the same explanatory process, albeit at different ends of a "seriousness" continuum".

Many authors differentiate between social disorder and physical disorder, but this division is not always entirely parallel. In Disorder and Decline, Skogan (1990) states that physical disorder refers to visible signs of neglect and decay such as dilapidation of buildings and public littering, while social disorder relates to certain behaviors or their consequences (such as public drunkenness, prostitution, graffiti, and vandalism). For Ross and Jang (2000) and Sampson (2009), among others, the consequences of certain behaviors, such as graffiti or vandalism, are forms of physical disorder and social 
disorder is only when there is interaction between individuals (for instance, loitering youngsters, drug deals, intimidation). Yet, other authors minimize the significance of the distinction between physical and social disorder (Xu, Fiedler, \& Flaming, 2005) or emphasize that this duality does not emerge from their analyses (Spelman, 2004).

Another important distinction is that between legally penalized disorder and phenomena that can be regarded as troubling, but do not infringe the law. In Félonneau's (2004) description of incivility, the emphasis falls on this aspect: "Incivilities are acts of nonrespect or of aggression towards others and towards the environment, without necessarily reflecting the legal category of delinquency or criminality" (p. 45). So, if drug use or drug dealing is a form of disorder that falls within the scope of criminal law, youngsters "loitering" are generally not infringing any law and, therefore, are not as such criminals.

\section{Determinants of Perceived Disorder}

Disorder is, to a large extent, a subjective concept. What one perceives as disorder depends greatly on the prior experiences that one brings to an encounter with potentially problematic behavior and is, therefore, different for each individual. Pleysier and Declerck (2006), therefore, speak of disorder as a perceived reality that gains shape, content, and meaning at the moment and by the manner in which it is made explicit and discursively expressed.

The perceived reality is influenced by not only the objective presence of disorder in a neighborhood but also the characteristics of the inhabitants and of the neighborhood itself. On the basis of personal interviews, census data, police records, and systematic neighborhood observations in Chicago, Sampson, and Raudenbush (2004) conclude, for example, that objectively observed disorder is a considerable predictor of perceived disorder, but that neighborhood context is even more important: "As the concentration of minority groups and poverty increases, residents of all races perceive heightened disorder even after we account for an extensive array of personal characteristics and independently observed neighborhood conditions" (p. 319).

Among residents, Sampson and Raudenbush (2004) found effects of age, marital status, and gender: the elderly, widows/widowers, and men perceived more disorder than, respectively, the young, the divorced, and women. There was also an effect from ethnic background: Black residents perceived less disorder than White residents in the same residential blocks.

Franzini, O'Brien Caughy, Nettles, and O'Campo (2007) repeated Sampson and Raudenbush's (2004) work in Baltimore. Using the same methodology they, too, found that perceptions of disorder were not only based on objectively observed disorder, but were dependent on the characteristics of individuals and on the social structure of the neighborhood. Those with higher educational attainment, Blacks, people who frequently move address, and those who are married or divorced perceived less disorder than, respectively, those with lower educational attainment, Whites, those who seldom or never change address, and widows or widowers. At the level of the neighborhood, only the social-economic structure was significant: residents of poorer neighborhoods perceived more disorder than did residents of wealthier neighborhoods. The ethnic composition of the neighborhood had no effect on perceived disorder.

Although the studies of Sampson and Raudenbush (2004) and Franzini et al. (2007) were carried out in large cities (Chicago and Baltimore), Reisig and Cancino 
(2004) went looking for the explanatory factors behind perceptions of disorder in more sparsely populated areas ("nonmetropolitan communities"). On the basis of survey data, census data, and crime statistics, these researchers also found effects at the level of residents and neighborhoods. For residents, the analyses indicated an influence from ethnic background and age. The remarkable thing is that, here, the effects were the opposite of those found in big cities: members of minority groups and younger individuals perceived more neighborhood disorder than did, respectively, the majority population or older individuals. At the level of neighborhood, residents of deprived areas, neighborhoods with high crime rates, and neighborhoods with little social cohesion, perceived more disorder than did residents of wealthier areas, neighborhoods with low crime rates, and neighborhoods with strong social cohesion.

\section{Disorder and Fear of Crime}

Already in the early 20th century, scholars of the Chicago School introduced the view that social ecological conditions of a neighborhood affect and shape the direction of crime rates (e.g., Park \& Burgess, 1921). However, it was the broken windows theory of Wilson and Kelling (1982) that provided one of the most influential theories with respect to the relationship between disorder and crime. According to this theory, the prevalence of disorder in a neighborhood will lead to a downwards spiral of decay. Phenomena such as graffiti, fly tipping, or broken windows signal to passersby that there is no social control, that nobody cares about the neighborhood, and that "anything goes". This leads to fear of crime and opens the way for more disorder and (more serious) crime. The theory is named from the finding that once a building has one broken window (if it is not replaced), it will soon have more.

Taylor et al. (1985) were the first researchers to find a connection between disorder and crime. In the city of Baltimore, they found that physical disorder registered at the neighborhood level correlated with levels of crime recorded by the police. ${ }^{1}$ A similar study in Chicago by Sampson and Raudenbush (1999) found that the number of observed incidences of disorder registered at neighborhood level was related to the number of (police) reported thefts and murders.

Keizer, Lindenberg, and Steg (2008) have provided empirical evidence, in research on the Dutch city of Groningen, that there is not simply statistical correlation between occurrences of disorder and crime, but a causal link. On the basis of various field experiments, these researchers showed that visible graffiti leads to an increase in littering and theft.

Another way in which the broken windows theory is being explored in empirical studies is by measuring perceptions, for instance, by linking the perception of disorder to fear of crime. One such example is the work of LaGrange et al. (1992), who found, on the basis of a nationwide telephonic survey in the United States, that the perceived prevalence of physical and social disorder had a positive effect on the estimated likelihood of becoming a victim of crime (risk of crime) and fear of crime.

Perkins and Taylor (1996) assessed physical and social neighborhood disorder through perception surveys as well. In Baltimore, they compared this measure of disorder with newspaper stories of disorder and observations by trained observers on site. Their study demonstrated that all three measures of disorder had relatively

\footnotetext{
${ }^{1}$ In a later study Taylor (2000) suggested that in Baltimore economic decline, rather than physical decay or social disorder, lead to higher crime.
} 
similar effects on fear of crime: The more indications of neighborhood disorder, the more fearful people were.

Ross and Jang (2000), who studied the connections between neighborhood disorder, fear of crime, and interpersonal trust in Illinois, also came to the conclusion that, after controlling for a series of sociodemographic variables, experiencing greater neighborhood disorder relates to higher levels of fear of crime and greater mistrust of others. Studies in Great Britain, Australia, Germany, and Canada, among other places, reached similar conclusions concerning the relationship between perceptions of (neighborhood) disorder and fear of crime (Markowitz, Bellair, Liska, \& Liu, 2001; McRea, Shyy, Western, \& Stimson, 2005; Ludemann, 2006; Fitzgerald, 2008).

\section{METHOD}

The data of this study were derived from the Flemish Integration Survey 2008, a standardized face-to-face survey designed by the Policy Research Centre on Equal Opportunities to monitor the social-cultural distance between ethnic minority groups and the Flemish majority and the way they live together in Flanders, the Dutchspeaking part of Belgium (Vancluysen, Van Craen, \& Ackaert, 2009). The survey was conducted in three Flemish cities with large populations of Moroccan and Turkish descent: Antwerp, Genk, and Ghent. ${ }^{2}$

The focus is on persons of Moroccan and Turkish descent because they form the two largest ethnic minority groups in Belgium (Perrin, 2007). Moroccan and Turkish migration to Belgium started in the early 1960s, when the Belgian government signed bilateral agreements with Morocco and Turkey to meet the need for labor in the expanding industries. In 1974, when industrial employment was shrinking, the government issued a moratorium on immigration. Still, this measure implied no turning point in immigration flows from Morocco and Turkey. After 1974 and well into present, Moroccan and Turkish immigrants come to Belgium on the basis of family reunification or marriage migration (Reniers, 1999). Nowadays, Moroccans and Turks are still among the largest newcomer groups in the Flemish region (Willems, 2008).

The Flemish reference group is a subgroup of the native Flemish population in Antwerp, Genk, and Ghent. The sample comprises respondents with a comparable frame of reference in terms of living environment and ethnic heterogeneity of the neighborhood. Members of the majority group were selected in those neighborhoods where the proportion of long-term unemployment is higher than the urban average and where the average taxable income is lower than the urban average. Hence, these neighborhoods are essentially multicultural neighborhoods.

In total, the sample comprised 1,260 persons (420 of Moroccan descent, 420 of Turkish descent, and 420 of Flemish descent). The whole sample, a disproportionately stratified random sample, comprised nine partial samples: per city and per ethnic group, a separate sample (representative with regards to age and gender) was made within the age category of 18 to 70 years old. The criteria applied by the civic

\footnotetext{
${ }^{2}$ According to the municipal registers, in 2008 Antwerp had a population of 35,803 people with a Moroccan and 11,689 people with a Turkish background (out of a total population of 471,100). In Genk there live 3,025 people with a Moroccan and 10,632 people with a Turkish background (out of a total population of 64,287 ) and Ghent counts 3,637 people of Moroccan and 13,718 people of Turkish descent (out of a total population of 237,250$)$.
} 
Table 1. Sample Characteristics $(N=960)$

\begin{tabular}{|c|c|c|c|c|c|c|}
\hline & \multicolumn{2}{|c|}{ Flemish descent } & \multicolumn{2}{|c|}{ Moroccan descent } & \multicolumn{2}{|c|}{ Turkish descent } \\
\hline & $N$ & $\%$ & $N$ & $\%$ & $N$ & $\%$ \\
\hline \multicolumn{7}{|l|}{ Gender } \\
\hline Male & 175 & 51.3 & 138 & 53.1 & 177 & 49.7 \\
\hline Female & 166 & 48.7 & 122 & 46.9 & 179 & 50.3 \\
\hline \multicolumn{7}{|l|}{ Age } \\
\hline $18-30$ & 89 & 26.1 & 118 & 45.4 & 143 & 40.2 \\
\hline $31-50$ & 134 & 39.3 & 104 & 40.0 & 167 & 46.9 \\
\hline $51-70$ & 118 & 34.6 & 38 & 14.6 & 46 & 12.9 \\
\hline \multicolumn{7}{|l|}{ Level of education } \\
\hline Up to primary & 47 & 14.0 & 91 & 37.0 & 123 & 35.3 \\
\hline Lower secondary & 75 & 22.3 & 53 & 21.5 & 97 & 27.9 \\
\hline Upper secondary & 117 & 34.8 & 86 & 35.0 & 105 & 30.2 \\
\hline College/university & 97 & 28.9 & 16 & 6.5 & 23 & 6.6 \\
\hline \multicolumn{7}{|l|}{ (Perceived) financial situation } \\
\hline Very difficult to make ends meet & 27 & 8.1 & 21 & 10.3 & 37 & 11.5 \\
\hline Difficult to make ends meet & 51 & 15.3 & 47 & 23.0 & 65 & 20.1 \\
\hline Neither difficult nor easy to make ends meet & 86 & 25.8 & 58 & 28.4 & 134 & 41.5 \\
\hline Easy to make ends meet & 126 & 37.8 & 68 & 33.3 & 63 & 19.5 \\
\hline Very easy to make ends meet & 43 & 12.9 & 10 & 4.9 & 24 & 7.4 \\
\hline \multicolumn{7}{|l|}{ (Perceived) neighborhood composition } \\
\hline Almost exclusively non-Flemish & 23 & 6.8 & 23 & 9.3 & 39 & 11.2 \\
\hline More non-Flemish than Flemish & 102 & 30.2 & 72 & 29.1 & 104 & 30.0 \\
\hline Almost as many non-Flemish as Flemish & 107 & 31.7 & 62 & 25.1 & 114 & 32.9 \\
\hline More Flemish than non-Flemish & 82 & 24.3 & 57 & 23.1 & 64 & 18.4 \\
\hline Almost exclusively Flemish & 24 & 7.1 & 33 & 13.4 & 26 & 7.5 \\
\hline \multicolumn{7}{|l|}{ City of residence } \\
\hline Antwerp & 113 & 33.1 & 85 & 32.7 & 113 & 31.7 \\
\hline Genk & 107 & 31.4 & 89 & 34.2 & 119 & 33.4 \\
\hline Ghent & 121 & 35.5 & 86 & 33.1 & 124 & 34.8 \\
\hline
\end{tabular}

population services to determine ethnic background were "current nationality" and "nationality at birth". 3

The fieldwork was administered between March and July 2008. The final sample comprised 960 usable, face-to-face interviews: 260 individuals of Moroccan descent, 358 of Turkish descent, and 342 of Flemish descent. The nonresponse rates $(54 \%$ for the Flemish, $47 \%$ for the Turkish, and $64 \%$ for the Moroccan descendants) are common in survey research among hard to reach groups (see, e.g., Dagevos, Gijsberts, Kappelhof, \& Vervoort, 2007). ${ }^{4}$ Respondent dropout could skew the results if systematic in particular subcategories. A control showed that the answers of the respondents of Flemish descent had to be weighted according to gender, age, level of education, and city. The answers of the respondents of Moroccan and Turkish descent had to be weighted according to gender and city. There was no need to weigh these groups for age, and as no reliable data were available, it was not

\footnotetext{
${ }^{3}$ Since a drastic relaxation of Belgium's naturalization laws, large numbers of people of Turkish and Moroccan descent have acquired Belgian citizenship. To use "current nationality" as sole criterion would not be sufficient to build a realistic image of the target group.

${ }^{4}$ Respondents from the effective samples that could not be reached or refused were replaced by respondents with a similar age and gender from the reserve samples.
} 
possible to control for level of education. Table 1 presents the characteristics of the samples.

\section{RESULTS}

\section{Perceived Disorder}

To chart perceived disorder, we presented respondents with a number of types of disorder. We asked the respondents how often (never, a few times, several times, often, or very often) they had been bothered in their neighborhood within the past 12 months by

- loitering youths,

- drug use and drug dealing,

- dog mess on streets and squares,

- public littering, and

- dilapidation of buildings and dwellings. ${ }^{5}$

A bivariate analysis showed that $34 \%$ of those of Moroccan descent and $45 \%$ of Turkish descent had felt discomfort in the neighborhood where they live because of loitering youths (see Table 2). Among those of Flemish descent, 50\% of the respondents had felt discomfort because of loitering youths, significantly more than the proportion of members of the Moroccan community $\left(\mathrm{chi}^{2}=15.84\right.$; degree of freedom $[d f]=4 ; p=.003)$. There was no significant difference between the Flemish majority and the Turkish community.

Drug use or drug dealing in the neighborhood had discomforted $27 \%$ of the majority group, $23 \%$ of the Moroccan community, and $31 \%$ of the Turkish community. The differences between the ethnic communities were not statistically significant.

Members of the Turkish community felt significantly higher levels of discomfort because of $\operatorname{dog}$ mess than did members of the majority group $\left(\mathrm{chi}^{2}=24.43 ; d f=4\right.$; $p=.000$ ). No less than $36 \%$ of members of the Turkish community (often) felt discomfort because of this cause, as against $23 \%$ of the Flemish majority. Interviewees of Flemish descent in their turn were significantly more bothered by this type of disorder than were those of Moroccan descent $\left(\mathrm{chi}^{2}=13.54 ; d f=4 ; p=.009\right)$. Among the latter, $19 \%$ of the respondents had in the past year (often) felt discomfort because of dog mess.

Public littering was more often a source of concern for Flemish descendants than for Turkish descendants $\left(\mathrm{chi}^{2}=8.04 ; d f=4 ; p=.090\right)$ and Moroccan descendants $\left(\mathrm{chi}^{2}=48.86 ; d f=4 ; p=.000\right)$. This phenomenon had been a source of discomfort at least once to about $86 \%$ of Flemish respondents, as against $80 \%$ of those of Turkish and $61 \%$ of those of Moroccan descent.

\footnotetext{
${ }^{5}$ This is not an exhaustive list of phenomena of disorder. As the questionnaire was drawn up in the framework of research into social cohesion of majority and minority groups, the number of items was limited.
} 
Table 2. Perceived Disorder. Frequency Distribution for Each Ethnic Group

\begin{tabular}{|c|c|c|c|c|}
\hline & Flemish descent & Moroccan descent & Turkish descent & Total \\
\hline \multicolumn{5}{|c|}{ Loitering youths } \\
\hline Never & $50.4 \%$ & $66.3 \%$ & $55.4 \%$ & $56.6 \%$ \\
\hline A few times & $25.2 \%$ & $18.2 \%$ & $21.0 \%$ & $21.8 \%$ \\
\hline Several times & $8.5 \%$ & $5.4 \%$ & $8.5 \%$ & $7.7 \%$ \\
\hline Often & $7.6 \%$ & $5.8 \%$ & $8.0 \%$ & $7.3 \%$ \\
\hline Very often & $8.2 \%$ & $4.3 \%$ & $7.1 \%$ & $6.7 \%$ \\
\hline \multirow[t]{2}{*}{ Total } & 341 & 258 & 352 & 951 \\
\hline & $100 \%$ & $\begin{array}{c}100 \% \\
\mathrm{chi}^{2}=16.99 ; d f=\end{array}$ & $.030100 \%$ & $100 \%$ \\
\hline \multicolumn{5}{|c|}{ Drug use and drug dealing } \\
\hline Never & $73.4 \%$ & $77.4 \%$ & $68.9 \%$ & $72.8 \%$ \\
\hline A few times & $14.2 \%$ & $13.3 \%$ & $12.8 \%$ & $13.4 \%$ \\
\hline Several times & $4.3 \%$ & $3.6 \%$ & $6.4 \%$ & $4.9 \%$ \\
\hline Often & $4.3 \%$ & $2.4 \%$ & $6.7 \%$ & $4.7 \%$ \\
\hline Very often & $3.7 \%$ & $3.2 \%$ & $5.2 \%$ & $4.2 \%$ \\
\hline \multirow[t]{3}{*}{ Total } & 323 & 248 & 344 & 915 \\
\hline & $100 \%$ & $100 \%$ & $100 \%$ & $100 \%$ \\
\hline & & $\operatorname{chi}^{2}=11.67 ; d f=$ & .167 & \\
\hline \multicolumn{5}{|c|}{ Dog mess on streets and squares } \\
\hline Never & $28.8 \%$ & $38.9 \%$ & $24.9 \%$ & $30.0 \%$ \\
\hline A few times & $28.2 \%$ & $29.6 \%$ & $23.8 \%$ & $26.9 \%$ \\
\hline Several times & $19.9 \%$ & $12.6 \%$ & $15.3 \%$ & $16.2 \%$ \\
\hline Often & $13.4 \%$ & $7.7 \%$ & $12.2 \%$ & $11.4 \%$ \\
\hline Very often & $9.8 \%$ & $11.3 \%$ & $23.8 \%$ & $15.5 \%$ \\
\hline \multirow[t]{3}{*}{ Total } & 337 & 247 & 353 & 937 \\
\hline & $100 \%$ & $100 \%$ & $100 \%$ & $100 \%$ \\
\hline & & $\operatorname{chi}^{2}=46.66 ; d f=$ & .000 & \\
\hline \multicolumn{5}{|l|}{ Public littering } \\
\hline Never & $14.4 \%$ & $38.6 \%$ & $20.5 \%$ & $23.2 \%$ \\
\hline A few times & $22.0 \%$ & $33.5 \%$ & $25.9 \%$ & $26.5 \%$ \\
\hline Several times & $19.1 \%$ & $13.4 \%$ & $17.1 \%$ & $16.8 \%$ \\
\hline Often & $21.7 \%$ & $5.1 \%$ & $17.9 \%$ & $15.9 \%$ \\
\hline Very often & $22.9 \%$ & $9.4 \%$ & $18.5 \%$ & $17.7 \%$ \\
\hline \multirow[t]{3}{*}{ Total } & 341 & 254 & 351 & 946 \\
\hline & $100 \%$ & $100 \%$ & $100 \%$ & $100 \%$ \\
\hline & & $\mathrm{chi}^{2}=90.54 ; d f=$ & .000 & \\
\hline \multicolumn{5}{|c|}{ Dilapidation of buildings and dwellings } \\
\hline Never & $59.6 \%$ & $70.2 \%$ & $66.8 \%$ & $65.1 \%$ \\
\hline A few times & $22.6 \%$ & $16.7 \%$ & $19.9 \%$ & $20.0 \%$ \\
\hline Several times & $9.2 \%$ & $5.2 \%$ & $5.5 \%$ & $6.7 \%$ \\
\hline Often & $4.5 \%$ & $2.4 \%$ & $4.0 \%$ & $3.7 \%$ \\
\hline Very often & $4.2 \%$ & $5.6 \%$ & $3.8 \%$ & $4.4 \%$ \\
\hline \multirow[t]{3}{*}{ Totaal } & 337 & 252 & 346 & 935 \\
\hline & $100 \%$ & $100 \%$ & $100 \%$ & $100 \%$ \\
\hline & & $\mathrm{chi}^{2}=12.89 ;$ & 116 & \\
\hline
\end{tabular}

Note. $\mathrm{df}=$ degree of freedom.

The proportion of respondents who had at least once felt discomfort at dilapidation of buildings or dwellings was around $40 \%$ for those of Flemish descent, $33 \%$ for those of Turkish descent, and 30\% for those of Moroccan descent. Only the difference between the Flemish majority group and the Moroccan community was statistically significant $\left(\mathrm{chi}^{2}=10.49 ; d f=4 ; p=.033\right)$. 
To investigate whether there is a net effect from ethnic background, we carried out a regression analysis of those issues which showed (bivariate) significant differences in perception-loitering youths, dog mess, littering, and dilapidation of real estate-, controlling for a number of variables that have been shown in the literature to have a possible effect on perceptions of disorder (see above).

We included the following variables: gender $(0=$ woman or $1=$ man $)$, age, level of education, financial situation (subjective estimation; from $1=$ very difficult to make ends meet to $5=$ very easy to make ends meet), the ethnic composition of the neighborhood (subjective estimation; from $1=$ almost everybody of non-Flemish descent to $5=$ almost everybody of Flemish descent), and the city of residence (Antwerp, Ghent, or Genk = reference). The results of the regression analyses can be seen in Table 3.

The analyses showed that after adding the controls, the only difference to disappear was that between those of Flemish and those of Moroccan descent regarding dilapidation of real estate. The other differences between ethnic majority and minority group members remained.

The analysis also brought out the fact that women were more bothered than men by $\operatorname{dog}$ mess and public littering. Respondents who claim to have few financial difficulties were also less bothered by dog mess and litter than were those who see themselves as having trouble making ends meet. Those who live in immigrant neighborhoods more often felt discomfort because of loitering youths, public littering, and dilapidation of real estate than did those in "White" neighborhoods. Finally, people living in Genk were less bothered by these four issues than those living in the more urbanized cities Antwerp and Ghent.

\section{Impact of Perceived Disorder on Fear of Crime}

The broken windows theory would predict that the perception of disorder increases fear of crime (see above). One might, however, question whether perception of disorder would have the same impact on different ethnic groups. To address this question, we carried out a regression analysis for each of the ethnic groups, using fear of crime as dependent variable. Fear of crime was measured by directly asking the respondents about their feeling of safety ("In this neighborhood, where you live, do you feel: (1) very unsafe, (2) unsafe, (3) neither unsafe nor safe, (4) safe, or (5) very safe?") ${ }^{6}$

A chi-square analysis made it clear that about $5 \%$ of those of Moroccan descent, $12 \%$ of those of Flemish descent, and $14 \%$ of those of Turkish descent felt (very) unsafe in the neighborhood where they live (see Table 4). Members of the Moroccan community felt significantly safer than did members of the other two ethnic groups. ${ }^{7}$ The difference between Turkish and Flemish descendants was not significant.

We included two scales in the explanatory analysis of fear of crime, constructed on the basis of the five issues discussed. Factor analyses (method: maximum likelihood;

\footnotetext{
${ }^{6}$ We are aware that, although there are studies in which only one item is used to measure fear of crime (including the National Crime Victimization Survey and the General Social Survey in the United States), this approach has already given rise to critical remarks (Ferraro \& LaGrange, 1987). Like other researchers, we opted for a single-item approach out of considerations of comparability and the principle of "economy" (Pleysier, 2009). We also see it as beneficial that a single general question allows respondents to give their own interpretation of (sources of) fear of crime.

${ }^{7}$ Difference between those of Flemish and those of Moroccan descent: chi $^{2}=18.60 ; d f=4 ; p=.001 ;$ difference between those of Moroccan and those of Turkish descent: $\operatorname{chi}^{2}=37.95 ; d f=4 ; p=.000$.
} 


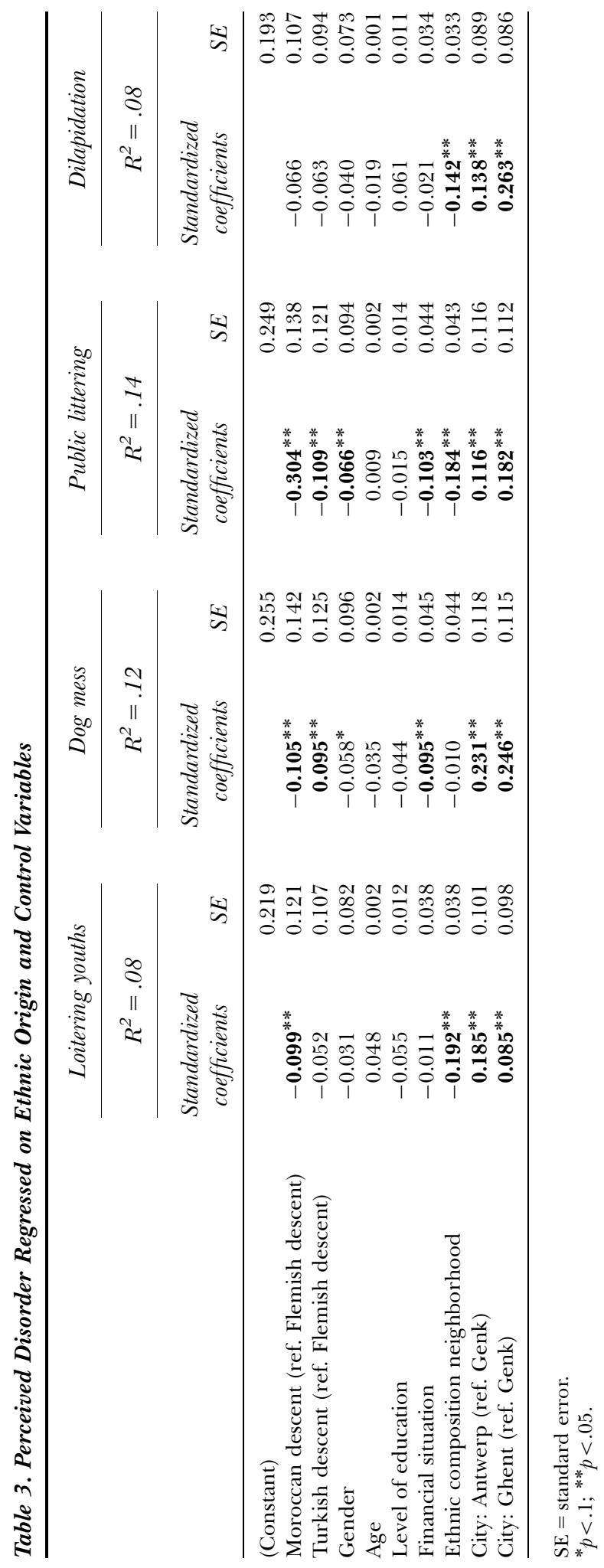


Table 4. Neighborhood Fear of Crime. Frequency Distribution Per Ethnic Group

\begin{tabular}{|c|c|c|c|c|}
\hline & Flemish descent & Moroccan descent & Turkish descent & Total \\
\hline Very safe & $17.1 \%$ & $29.7 \%$ & $11.7 \%$ & $18.4 \%$ \\
\hline Safe & $55.5 \%$ & $50.0 \%$ & $54.4 \%$ & $53.7 \%$ \\
\hline Neither unsafe nor safe & $15.5 \%$ & $15.4 \%$ & $19.8 \%$ & $17.1 \%$ \\
\hline Unsafe & $8.5 \%$ & $3.3 \%$ & $10.6 \%$ & $7.9 \%$ \\
\hline Very unsafe & $3.4 \%$ & $1.6 \%$ & $3.2 \%$ & $2.8 \%$ \\
\hline \multirow[t]{3}{*}{ Total } & 328 & 246 & 349 & 923 \\
\hline & $100 \%$ & $100 \%$ & $100 \%$ & $100 \%$ \\
\hline & \multicolumn{4}{|c|}{$\operatorname{chi}^{2}=40.70 ; d f=8 ; p=.000$} \\
\hline
\end{tabular}

Note. $\mathrm{df}=$ degree of freedom.

rotation: varimax) showed that the five items measured the same concepts in the three communities. Among both the Flemish majority group and the two minority groups, there was a distinction between social disorder (loitering youths and drug use and dealing) and physical disorder (dog mess, litter, and dilapidation). The factor loadings are provided in an Appendix.

To measure the effect of perceptions of disorder on fear of crime, we carried out a number of regression analyses. The control variables included in the analyses were gender $(0=$ woman or $1=$ man), age, level of education, financial situation (subjective estimation; from $1=$ very difficult to make ends meet to $5=$ very easy to make ends meet), the ethnic composition of the neighborhood (subjective estimation; from $1=$ almost everybody of non-Flemish descent to $5=$ almost everybody of Flemish descent), and the city of residence (Antwerp, Ghent, or Genk = reference):

Gender and age. In the research tradition on fear of crime, "gender" and "age" are regarded as two of the most influential and most widely used predictors of fear of crime: women and the elderly have higher levels of fear than men and the young (LaGrange \& Ferraro, 1989; Ditton \& Farrall, 2000).

Level of education and subjective estimation of one's financial situation. Studies have shown that a high level of education and/or high income correlate to less fear of crime (Will \& McGrath, 1995; Pantazis, 2000).

Perception of the ethnic composition of the neighborhood. The finding has been made that those living in immigrant neighborhoods have higher levels of fear than those living in socalled "White" neighborhoods (Merry, 1981; Quillian \& Pager, 2001; Eitle \& Taylor, 2008).

City. Studies in the United States, the Netherlands, and Italy have shown that those living in more rural areas report lower fear of crime than those living in more urbanized settings (LaGrange \& Ferraro, 1989; Wittebrood, 2000; Miceli, Roccato, \& Rosato, 2004). We would, therefore, expect inhabitants of Genk to have lower levels of fear than inhabitants of the more urbanized cities Antwerp and Ghent. ${ }^{8}$

We give the results of the regression analyses in Table 5 (Flemish community), Table 6 (Moroccan community), and Table 7 (Turkish community). In the first step, we included only control variables, in the second and third steps, we investigated the

\footnotetext{
${ }^{8}$ Genk is a small city of 64,287 inhabitants, whereas Antwerp and Ghent are the two largest cities in Flanders, with a respective population of 471,000 and 237,250 inhabitants.
} 


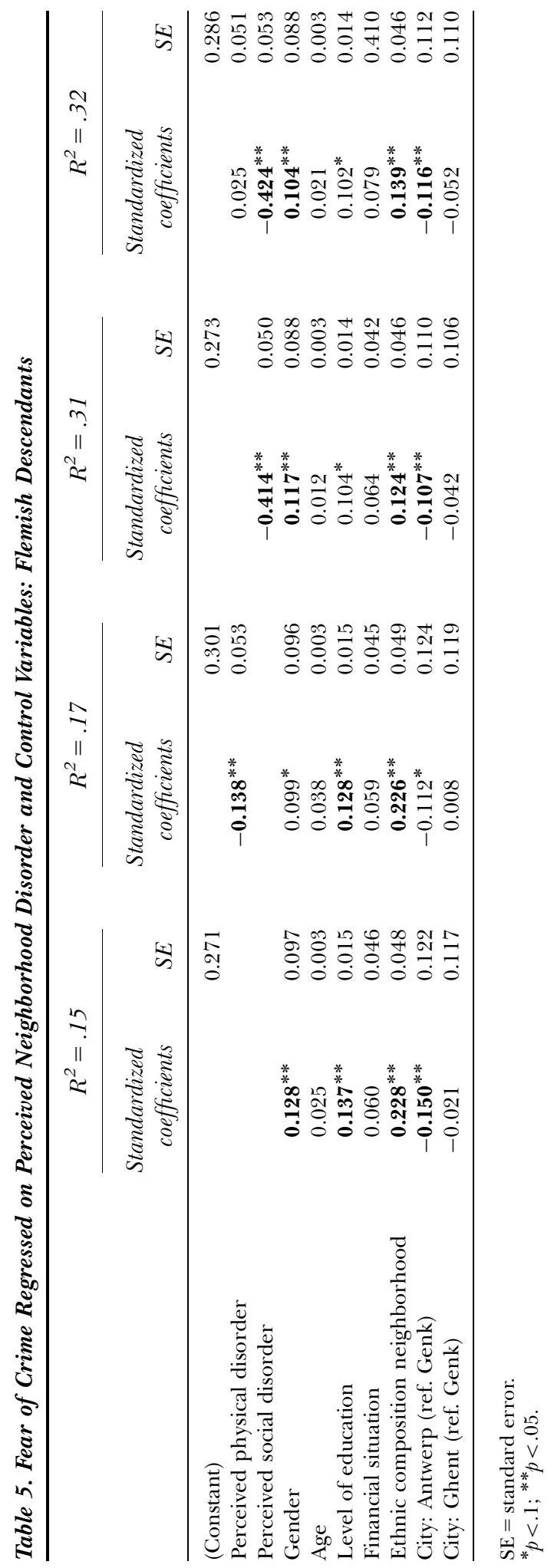




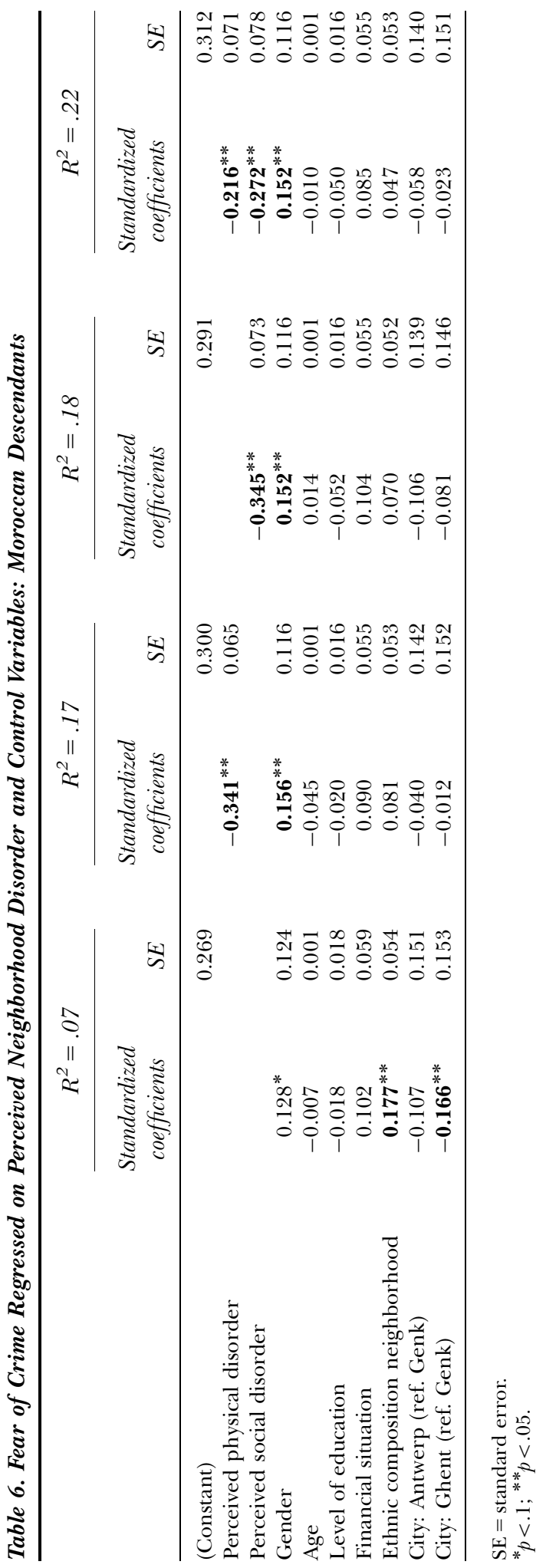




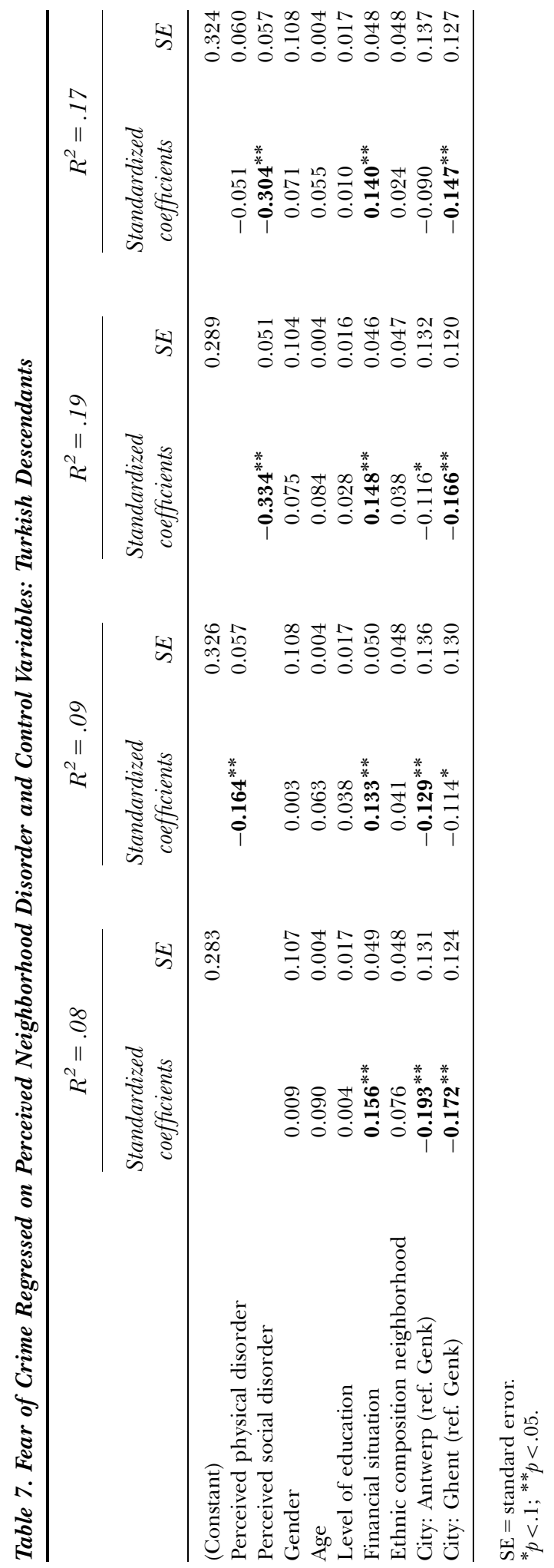


impact of the perception of physical and social disorder, respectively, and in the fourth step, we included the controls and the two disorder variables.

The analyses showed statistically significant effects of perceived disorder on fear of crime among all ethnic groups: the more perceived disorder, the more fearful the respondents were. The share of fear of crime that was explained by the perception of disorder did, however, vary. After the addition of both disorder variables, the explained variation rose among those of Flemish descent by 17 percentage points (from $R^{2}=.15$ to $R^{2}=.32$ ), as against 15 and 9 percentage points, respectively, among those of Moroccan and Turkish descent. ${ }^{9}$ Furthermore, the explained variation and the standardized regression coefficients made clear that among those of Flemish and Turkish descent, the perception of social disorder had far more impact on fear of crime than did the perception of physical disorder. Among those of Moroccan descent, both types of disorder had approximately equal weight.

In the three ethnic groups, different control variables influenced fear of crime. In the final model (with both disorder variables) of the Flemish group, women, those who see their neighborhood as an "immigrant neighborhood", and those who live in Antwerp, all had higher levels of fear in the neighborhood where they live than did, respectively, men, those who see their neighborhood as a "White area", and those who live in Genk. Among those of Moroccan descent (in the final model), women felt less safe than men. In the Turkish community, those who say they have trouble making ends meet and those who live in Ghent had higher levels of fear than those who, respectively, claim to be financially more secure and who live in Genk.

\section{CONCLUSION AND DISCUSSION}

In this study, we investigated two research questions: (a) Does the perception of neighborhood disorder differ between members of the Flemish majority and Moroccan/Turkish descendants? and (b) Does perceived disorder have the same impact on fear of crime among majority group members as among Moroccan/Turkish minority group members? Concerning the first research question, we can conclude that loitering youths, dog mess, and public littering were of more frequent concern to those of Flemish descent than those of Moroccan descent. Compared with those of Turkish descent, members of the Flemish majority group were more bothered by littering, but less bothered by dog mess. With respect to the second research question, the analyses supported the broken windows theory for all three ethnic groups. Those of Flemish, Moroccan, and Turkish descent had higher levels of fear in the neighborhoods where they live the more they were bothered by disorder.

Majority group members rather frequently experienced disorder and these irritations explained a large part of their relatively high levels of fear of crime. Persons of Moroccan descent reported comparably little disorder and a relatively weak fear of crime, but when they did experience fear of crime, this could, in large part, be ascribed to experiences of disorder. Finally, Turkish descendants were rather often bothered by disorder and felt relatively unsafe, but their experiences of disorder explained only a "limited" part of their fear of crime. The difference between members of the Turkish minority group and the Flemish majority lay primarily in the effect of the perception

\footnotetext{
${ }^{9}$ We remark that the explained variation among those of Turkish descent increased by 11 percentage points when only the perception of social disorder was added.
} 
of social disorder. Although those of Turkish descent were as irritated by the sight of loitering youths as were those of Flemish descent, they were not so inclined to be frightened of them.

The question remains how the differences identified should be understood. Why is it, for instance, that some ethnic groups experienced more or less disorder than others? We will, here, propose a number of hypotheses to be tested by further research.

A first possibility for the differing perceptions of disorder is a difference in the actual occurrence of phenomena of disorder. Specifically, this would mean, for instance, that Flemish descendants are more bothered by dog mess than are Moroccan descendants because there is more dog mess in the streets, where the respondents of Flemish descent live. The perception of greater disorder would then be a consequence of being faced more often with sources of disorder. To test this hypothesis, independent observers would have to measure the amounts of dog mess, litter, number of (groups of) loitering youths, and so forth, on the ground (see e.g., Perkins \& Taylor, 1996; Sampson \& Raudenbush, 2004). This was not, however, an option within the constraints of the present study.

A second possible explanation is the past significance of experiences of disorder. Sampson and Raudenbusch (2004) remark that "groups are judging disorder by the norms that have been generated in past, segregated environments" (p. 329) It is not inconceivable that the same number of sources of disorder will be experienced as more problematic by a group that, in the past, was exposed to far fewer sources of disorder than to a group that has faced them more often. In terms of our study, this could, for instance, mean that members of the Moroccan community perceived less disorder than members of the Flemish majority group because they compared their residential environment with a less pleasant environment in Morocco, while members of the majority group took their familiar formerly "White" neighborhood as their point of reference. To test this hypothesis, it might be useful to supplement a sociological-criminological approach with a historical approach and/or cultural anthropological approach.

Third, the process of integration into the society can have an impact. We deduce this from, among other things, the focus group discussions that were conducted a few years ago in Van Craen, Vancluysen, and Ackaert (2007) with minority and majority group members in Flanders. The youngest participants (aged 18-30 years) at that time stated that youths of Moroccan background more often loitered in the street than did youths of Turkish background. The reason that participants gave was related to the role of the mosque: While Turkish mosques often had social facilities attached where youngsters could meet, young people of Moroccan descent claimed not to have such facilities available to them, so that they were more often reduced to hanging about in the street. The fact that some ethnic groups are more involved in something that can be regarded as disorder probably has some influence on their perception of such behavior. A detailed study of the involvement of different groups and the dispersal or concentration of sources of disorder could, therefore, give us more insight into the issue being studied.

Finally, it seems worthwhile to investigate the role of cultural factors. If disorder is an infringement of the governing values and norms (see above), one might well expect the concept to be seen differently in different cultures. The governing values and norms do, after all, differ from culture to culture. The fact that those of Flemish descent were more or less bothered by certain phenomena of disorder than those of Moroccan or Turkish descent is, thus, possibly (partly) because of the implicit or explicit choices made by ethnic groups regarding desirable patterns of behavior, the rules of behavior that flow from these, and the mechanisms of social enforcement 
related to them. To gauge the importance of these elements, a cross-fertilization with cultural anthropology would again seem indicated.

The finding that the perception of social disorder had a stronger impact on fear of crime among Flemish descendants than among Moroccan or Turkish descendants, could-besides the fact that those of Moroccan descent perceived less social disorderbe related to the extent to which people had contacts with their neighbors. According to Ross and Jang (2000, p. 411), informal contacts with neighbors reduce the effect of perceptions of disorder on fear of crime:

When people form and maintain informal alliances with their neighborswhen they visit and talk to each other and help each other out-, they can buffer the negative effects of living in a dangerous neighborhood. At high levels of perceived disorder, people who form connections with neighbors have lower levels of fear and mistrust than those who do not.

Earlier analyses of the dataset used for this study showed that people with a Moroccan or Turkish background more often chat with their neighbors than do members of the majority group. The informal social capital of members of the Turkish community appears to be largest (Vancluysen et al., 2009).

Among Turkish descendants, there are likely to be other factors that explain fear of crime, which is of greater importance than perceptions of disorder. In the first place, we have in mind being the victim of crimes and incidents. Analyses by Van Craen and Ackaert (2006) have shown that the number of experiences of victimhood is unequally distributed among the various ethnic groups. People with a Turkish background are more often the victim of crime or an incident than are those from Flemish backgrounds. ${ }^{10}$ These experiences presumably affect their fear of crime. However this may be, it is clear that our results raise many new research questions that will require attention in the coming years.

\section{REFERENGES}

Bovenkerk, F. (2001). Organized crime and ethnic minorities: Is there a link? In P. Williams \& D. Vlassis (Eds.), Combating transnational crime: Concepts, activities and responses (pp. 109-126). London: Frank Cass.

Dagevos, J., Gijsberts, M., Kappelhof, J., \& Vervoort, M. (2007). Survey Integratie Minderheden 2006. Verantwoording van de opzet en de uitvoering van een survey onder Turken, Marokkanen, Surinamers, Antillianen en een autochtone vergelijkingsgroep. [Survey Integratie Minderheden 2006: Justification of the design and implementation of a survey among Turks, Moroccans, Surinamese, Antilleans and a native reference group.] Den Haag: SCP.

Ditton, J., \& Farrall, S. (2000). The fear of crime. Aldershot: Ashgate.

Eitle, D., \& Taylor, J. (2008). Are Hispanics the new "threat"? Minority group threat and fear of crime in Miami-Dade County. Social Science Research, 37(4), 1102-1115.

Félonneau, M.-L. (2004). Love and loathing of the city: Urbanophilia and urbanophobia, topological identity and perceived incivilities. Journal of Environmental Psychology, 24(1), 43-52.

Ferraro, K.F., \& LaGrange, R. (1987). The measurement of fear of crime. Sociological Inquiry, $57(1), 70-101$.

\footnotetext{
${ }^{10}$ The number of respondents of Moroccan descent in the dataset was too limited to draw any conclusions.
} 
Fitzgerald, R. (2008). Fear of crime and the neighborhood context in Canadian cities. Ottawa: Canadian Centre for Justice Statistics.

Franzini, L., O’Brien Caughy, M., Nettles, S., \& O’Campo, P. (2007). Perceptions of disorder: Contributions of neighborhood characteristics to subjective perceptions of disorder. Journal of Environmental Psychology, 28(1), 83-93.

Keizer, K., Lindenberg, S., \& Steg, L. (2008). The spreading of disorder. Science, 322, 1681-1685.

Kubrin, C.E. (2008). Making order of disorder: A call for conceptual clarity. Criminology \& Public Policy, 7(2), 203-214.

LaGrange, R.L., \& Ferraro, K.F. (1989). Assessing age and gender differences in perceived risk and fear of crime. Criminology, 27(4), 697-719.

LaGrange, R.L., Ferraro, K.F., \& Supancic, M. (1992). Perceived risk and fear of crime: Role of social and physical incivilities. Journal of Research in Crime and Delinquency, 29(3), 311-334.

Latkin, C.A., German, D., Hua, W., \& Curry, A.D. (2009). Individual-level influences on perceptions of neighborhood disorder: A multilevel analysis. Journal of Community Psychology, 37(1), 122-133.

Ludemann, C. (2006). Fear of crime in urban neighborhoods. A multilevel analysis. Kölner Zeitschrift für Soziologie und Sozialpsychologie, 58(2), 285-306.

Markowitz, F., Bellair, P., Liska, A., \& Liu, J. (2001). Extending social disorganization theory: Modelling the relationships between cohesion, disorder, and fear. Criminology, 39(2), 293-318.

McRea, R., Shyy, T.-K., Western, J., \& Stimson, R.J. (2005). Fear of crime in Brisbane: individual, social and neighborhood factors in perspective. Journal of Sociology, 41(1), 7-27.

Merry, S.E. (1981). Urban danger: life in a neighborhood of strangers. Philadelphia: Temple University Press.

Miceli, R., Roccato, M., \& Rosato, R. (2004). Fear of crime in Italy. Environment and Behavior, 36(6), 776-789.

Pantazis, C. (2000). "Fear of crime", vulnerability and poverty. Evidence from the British Crime Survey. British Journal of Criminology, 40(3), 414-436.

Paoli, L., \& Reuter, P. (2008). Drug trafficking and ethnic minorities in Western Europe. European Journal of Criminology, 5(13), 13-37.

Park, R., \& Burgess, E. (1921). Introduction to the science of sociology. Chicago: University of Chicago Press.

Perkins, D.G., \& Taylor, R.B. (1996). Ecological assessments of community disorder: Their relationship to fear of crime and theoretical implications. American Journal of Community Psychology, 24(1), 63-107.

Perrin, N. (2007). Migrations internationales et populations issues de l'immigration en Belgique: un aperçu statistique. [International migrations and immigrant populations in Belgium: A statistical approach.] Louvain-la-Neuve: GéDAP-UCL.

Pleysier, S. (2009). "Angst voor criminaliteit" onderzocht. De brede schemerzone tussen alledaagse realiteit en irrationeel fantoom. ["Fear of crime" investigated. The broad gray area between everyday reality and irrational phantom.] Leuven: Katholieke Universiteit Leuven.

Pleysier, S., \& Declerck, J. (2006). Over hondenpoep en hangjongeren. Een verkennend onderzoek naar overlastfenomenen in parken en groenzones. [About dog mess and loitering youths. An exploratory study on phenomena of disorder in parks and green areas.] Tijdschrift voor Veiligheid, (5)1, 5-20.

Quillian, L., \& Pager, D. (2001). Black neighbors, higher crime? The role of racial stereotypes in evaluations of neighborhood crime. American Journal of Sociology, 107(3), 717-767.

Reisig, M.D., \& Cancino, J.M. (2004). Incivilities in nonmetropolitan communities: The effects of structural constraints, social conditions, and crime. Journal of Criminal Justice, 32(1), 15-29. 
Reniers, G. (1999). On the history and selectivity of Turkish and Moroccan migration to Belgium. International Migration, 37(4), 679-713.

Ross, C.E., \& Jang, S.J. (2000). Neigborhood disorder, fear, and mistrust: The buffering role of social ties with neighbors. American Journal of Community Psychology, 28(4), 401-419.

Ross, C.E., \& Mirowsky, J. (1999). Disorder and decay: The concept and measurement of perceived neighborhood disorder. Urban Affairs Review, 34(3), 412-432.

Sampson, R.J. (2009). Disparity and diversity in the contemporary city: Social (dis)order revisited. The British Journal of Sociology, 60(1), 1-31.

Sampson, R.J., \& Raudenbush, S.W. (1999). Systematic social observation in public spaces: A new look at disorder in urban neighborhoods. American Journal of Sociology, 105(2), 603-651.

Sampson, R.J., \& Raudenbush, S.W. (2004). Seeing disorder: neighborhood stigma and the social construction of "broken windows". Social Psychology Quarterly, 67(4), 319-342.

Skogan, W.S. (1990). Disorder and decline. Crime and the spiral of decay in American neighborhoods. Los Angeles, CA: University of California Press.

Spelman, W. (2004). Optimal targeting of incivility-reduction strategies. Journal of Quantitative Criminology, 20(1), 63-87.

Taylor, R.B. (2000). Breaking away from broken windows: Baltimore neighborhoods and the nationwide fight against crime, grime, fear, and decline. Boulder, CO: Westview Press.

Taylor, R.B., Shumaker, S.A., \& Gottfredson, S.D. (1985). Neighborhood-level links between physical features and local sentiments: Deterioration, fear of crime, and confidence. Journal of Architectural Planning and Research, 2(4), 261-275.

Van Craen, M., \& Ackaert, J. (2006). De Veiligheidsscan. Instrument voor een lokaal veiligheids- en leefbaarheidsbeleid. [The Safety scan. Instrument for a local security and livability policy.] Antwerpen: Maklu.

Van Craen, M., Vancluysen, K., \& Ackaert, J. (2007). Voorbij wij en zij? De sociaal-culturele afstand tussen autochtonen en allochtonen tegen de meetlat. [Beyond us and them? The social-cultural distance between natives and immigrant descendants measured.] Brugge: Vanden Broele.

Vancluysen, K., Van Craen, M., \& Ackaert, J. (2009). Gekleurde steden. Autochtonen en allochtonen over samenleven. [Colored cities. Natives and immigrant descendants about living together.] Brugge: Vanden Broele.

Wahrman, H. \& Gross, Z. (Eds.). Educating toward a culture of peace (pp. 93-108). Charlotte, NC: Information Age Publishing Inc.

Werdmölder, H. (2006). Moroccan delinquent boys in Dutch society. In Y. Iram, H. Wahrman, \& Z. Gross (Eds.). Educating toward a culture of peace (pp. 93-108). Charlotte, NC: Information Age Publishing Inc.

Will, J.A., \& McGrath, J.H. (1995). Crime, neighborhood perceptions, and the underclass: The relationship between fear of crime and class position. Journal of Criminal Justice, 23(2), 163-176.

Willems, P. (2008). Migratiebewegingen in het Vlaamse Gewest in de periode 1997-2006. [Migration movements in the Flemish region in the period 1997-2006.] Brussel: Studiedienst van de Vlaamse regering.

Wilson, J.Q., \& Kelling, G. (1982). The police and neighborhood safety: Broken windows. The Atlantic Monthly, 127, 29-38.

Wittebrood, K. (2000). Buurten en geweldscriminaliteit: een multilevel-analyse. [Neighborhoods and violent crime: A multilevel analysis.] Mens en Maatschappij, 75(2), 92-102.

Wyant, B.R. (2008). Multilevel impacts of perceived incivilities and perceptions of crime risk on fear of crime. Journal of Research in Crime and Delinquency, 45(1), 39-64.

Xu, Y., Fiedler, M.L., \& Flaming, K.H. (2005). Discovering the impact of community policing: The broken windows thesis, collective efficacy, and citizens' judgment. Journal of Research in Crime and Delinquency, 42(2), 147-186. 


\section{APPENDIX}

Factor Analyses (Method: Maximum Likelihood; Rotation: Varimax) Perceived Neighborhood Disorder Per Ethnic Group

\begin{tabular}{|c|c|c|c|c|c|c|}
\hline & \multicolumn{2}{|c|}{ Flemish descent } & \multicolumn{2}{|c|}{ Moroccan descent } & \multicolumn{2}{|c|}{ Turkish descent } \\
\hline & factor 1 & factor 2 & factor 1 & factor 2 & factor 1 & factor 2 \\
\hline Loitering youths & 0.857 & 0.156 & 0.623 & 0.186 & 0.719 & 0.173 \\
\hline Drug use and drug dealing & 0.523 & 0.245 & 0.567 & 0.198 & 0.553 & 0.184 \\
\hline Dog mess & 0.081 & 0.707 & 0.275 & 0.411 & 0.152 & 0.416 \\
\hline Public littering & 0.298 & 0.601 & 0.178 & 0.984 & 0.139 & 0.990 \\
\hline Dilapidation of buildings & 0.214 & 0.449 & 0.449 & 0.550 & 0.260 & 0.351 \\
\hline$R^{2}$ & \multicolumn{2}{|c|}{65.2} & \multicolumn{2}{|c|}{67.3} & \multicolumn{2}{|c|}{62.8} \\
\hline
\end{tabular}

